Original Research Paper

\title{
IoT-Based Solar Energy
}

\author{
Ericka Ensimau Sekudan ${ }^{1}$, Ahmad Mirza Azhar ${ }^{1}$, Kaiyisah Baiduri Azahar ${ }^{1}$ \\ ${ }^{1}$ Department of Computer Science, Faculty of Art, Computing and Creative Industries, \\ Universiti Pendidikan Sultan Idris. Perak, Malaysia.
}

Article history
Received:

02.08 .2021

Revised:

08.09.2021

Accepted:

14.09.2021

*Corresponding Author: Ericka Ensimau Anak Sekudan Email:

ericka@gmail.com

This is an open access article, licensed under: $\mathrm{CC}-\mathrm{BY}$-SA
Abstract: Problems with a shortage of electricity often occur, especially in a rural area, which makes it difficult to do daily work and makes it difficult to communicate with outsiders. Problems with a shortage of electricity can affect the daily activities of residents, especially in rural areas, and can pose risks in the event of emergencies such as illnesses that require mechanical treatment. If this problem persists it could be detrimental to the population who do not have electricity. Electricity is very important as it can make it easier for people to do the work and for the people in the interior to get information. Problems with a shortage of electricity can affect communication networks such as the internet, radio waves, and mobile phone lines and so on. In the current state of technology development, the creation of technologies that can solve this problem must be done and referred to as Solar Energy. It is an IoT research that absorbs energy from the sun to produce electricity in every home. The movement of this research can be controlled manually by using a mobile phone connected to the internet and also controlled automatically by the direction of sunlight. With this, updates from users are a must. This meets the user's need for a device that can be used continuously.

Keywords: Computational Thinking, Industrial Revolution 4.0, Internet of Things, Solar Energy. 


\section{Introduction}

Solar energy is energy that comes from the sun. The solar energy will generate energy derived from the sun and send a message on how much voltage or energy is absorbed by the solar using the internet. Solar power is the fastest growing means of renewable energy. The research is designed and implemented using simple single axis solar tracker system. In order to maximize energy generation from sun, it is necessary to introduce solar tracking systems into solar power systems. Furthermore, the advantages of solar energy are renewable clean power that is available every day of the year, even cloudy days produce some power. Solar power is pollution free and causes no greenhouse gases to be emitted after installation.

The Internet of Things (IoT) is the concept of connecting any device to the internet and to other connected devices. The IoT is a network of connected things and people all of which collect and share data about the way they are used and about the environment around them. Furthermore, devices and objects with built in sensors are connected to an Internet of Things platform, which integrates data from the different devices and applies analytics to share the most valuable information with applications built to address specific needs. The Internet of Things (IoT) has evolved due to the convergence of multiple technologies, real-time analytics, machine learning, commodity sensor, and embedded systems.

\section{Literature Review}

\subsection{Internet of Things}

The IoT concept was coined by a member of the Radio Frequency Identification (RFID) development community in 1999, and it has recently become more relevant to the practical world largely because of the growth of mobile devices, embedded and ubiquitous communication, cloud computing and data analytics. We can imagine a whole world where billions of objects can sense, communicate and share information, all interconnected over public or private Internet Protocol (IP) networks. While Internet of Things (IoT) is a network of physical object, the internet is not only a network of computer, but it has evolved into a network of device [1].

Besides, Panessai et al [1] said Internet of Things is refer to the general idea of things, especially everyday objects, that are readable, recognisable, locatable, addressable through information sensing device and controllable via the Internet, irrespective of the communication means (whether via RFID, wireless LAN, wide area networks, or other means). However, Internet of Things is a new revolution of the Internet that objects make themselves recognizable and they obtain intelligence. The goal of the Internet of Things is to enable things to be connected anytime, anyplace, with anything and anyone ideally using any path/network and any service.

The Internet of Things (IoT) allows objects to be sensed and controlled remotely across existing network infrastructure, creating opportunities for more direct integration of the physical world into computer-based systems, and resulting in improved efficiency and accuracy. Then, IoT is able to interact without human intervention. There have some preliminary IoT applications have been already developed in healthcare, transportation, and automotive industries. However, there many new developments have taken place in the integration of objects with sensors on the Internet [3].

Table 1. Implementation of IoT Researchs in several Fields

\begin{tabular}{llll}
\hline \multicolumn{1}{c}{ Automation } & \multicolumn{1}{c}{ Health } & \multicolumn{1}{c}{ Productivity } & Disaster \\
\hline - Smart Garbage & $\bullet$ Displaying Health & - Smart Delivery & - Smart Water Level \\
monitoring [2]. & Status Based IoT [11]. & Agent [13]. & Indicator [16]. \\
- Intelligent egg incubator & • Smart Cane based on & - Smart Mirror for & \\
[3]. & IoT [12]. & Home Automation & \\
- Remote Control Systems & & [14]. \\
to feed birds [4]. & & - Smart Charger Based & \\
- Solar Panel Remote & & & \\
Monitoring and Control & & \\
System on Miniature & & \\
Weather Stations [5] [6] & & \\
[7] [8] [9] [10]. & & \\
\hline
\end{tabular}




\subsection{Device of Internet of Things}

Nowadays, we can see a lot of research that implied IoT concept. There are many devices that the developer used to build an IoT research. For this section will focus on the famous IoT platform that popular among IoT developer which is Arduino Uno.

Manisha Verma [17], once said, Arduino is basically an open-source microcontroller which consists of microcontroller chip. Arduino is design to provide inexpensive and easy way for students to create device which interact with their surrounding environment by using sensor. Arduino is used for constructing and programming electronic devices. Besides, arduino have software to develop a code which is known as Arduino IDE and stand for Integrated Development Environment that use C or $\mathrm{C}++$ language programming that runs on your computer and upload computer code to the physical board. Several types of Arduino can be used to develop a research and it makes the work easier. The difference between the Arduino Uno and the other Arduino is that Arduino Uno is consists of 14 digital I/O pin where 6 pins can be used for Pulse Width Modulation and 6 analog input pins, a reset button, power jack, USB connection. It requires to hold up the micro controller. With the help of USB cable Arduino is simply attach to PC and give the supply started with AC to DC battery.

\subsection{Interaction between IoT and Users}

This segment will discuss how the IoT research can be interact by the user. It can be divided into 3 categories which are short form, medium form and long form.

\section{Short Form}

Short form interactions occur when a user is not satisfied with current physical conditions. This is an immediate and urgent issue for the user and is one they are willing to spend time fixing. Since the user did not anticipate this need of interacting with the system, it is important to resolve the issue quickly since the user is likely already in a negative mental state and likely have not allotted mental time for interaction.

\section{Medium Form}

Medium form interactions occur when a user consciously decides to interact with the application. There are two goals the user has when performing this type of interaction: planning for future events and changing the recurring scheduling. These interactions differ from short term interactions in that the user has consistent and ongoing action.

It is essential that the user understands how the current system is functioning so they know what change they have to make. Once they have identified the deficiency, they should be able to change it quickly and validate that the system has been modified.

\section{Long Form}

Long form interactions should rarely, if ever, occur. These are actions that 30 seconds or more. Ideally, long form interactions are only performed by a user on initial setup of the system. This is when excitement in the product is still high and users are more willing to spend time configuring it to their unique preferences.

\subsection{Component}

There are several components used to develop the research based on IoT researchs like solar energy including Arduino Uno. For this part, there are several components used to make solar energy researchs:

- Arduino IDE

- Servo Motor

- Jumper Wires

- Breadboard

- Resistor

- Light Dependent Resistor (LDR) Sensor

- Current Sensor

- Solar Panel

- USB Type-B Cable

- Ultrasonic Sensor 


\subsection{Methodology Used to Develop an IoT}

\subsubsection{Waterfall Methodology}

Waterfall was the first tradition SDLC, as linear sequential process flow model for the software product development. Process flow is divided into several SDLC phases like requirement analysis, planning and scheduling, system design, implementation, testing, deployment and maintenance. The characteristics of Waterfall can be selected for the formations of Scrumbanfall are requirement analysis and documentation and project planning and charter [18] [19].

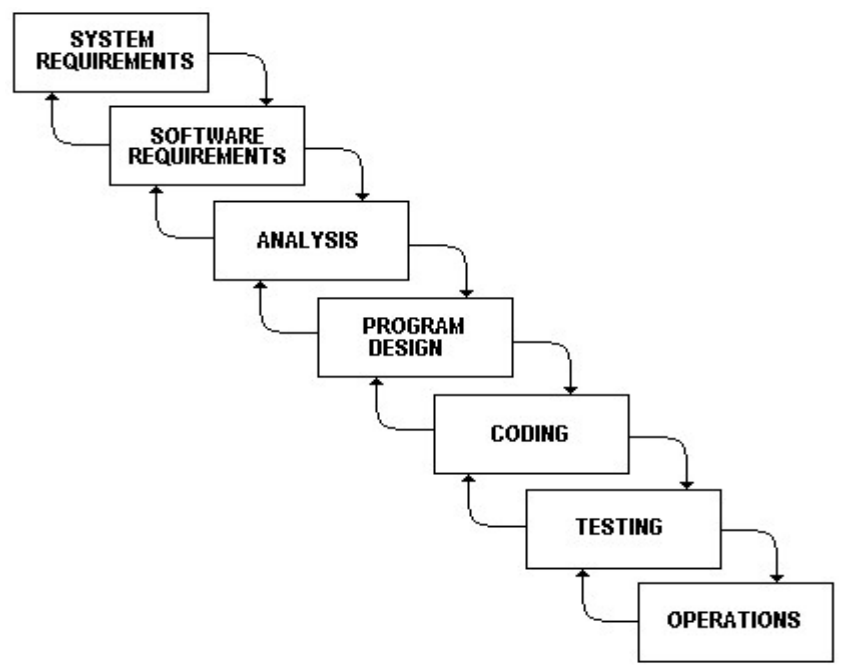

Figure 2. Waterfall Methodology

\subsubsection{Agile Methodology}

Agile project management approach is known for its adaptability to changes during the project life cycle and its innovative outcomes. Furthermore, Agile methodology that adopts the iterative approach, open collaboration, and process adaptability throughout the life-cycle of the project.

Agile methodology is flexible, an iterative method having no clear structure for carrying out the projects. This iterative agile approach is more flexible and its short time-span iterations seek improvement for the project in small release, with minimal planning, rather than plan at length. This helps to minimize the overall risk, and allows the project to adapt to changes more quickly [6].
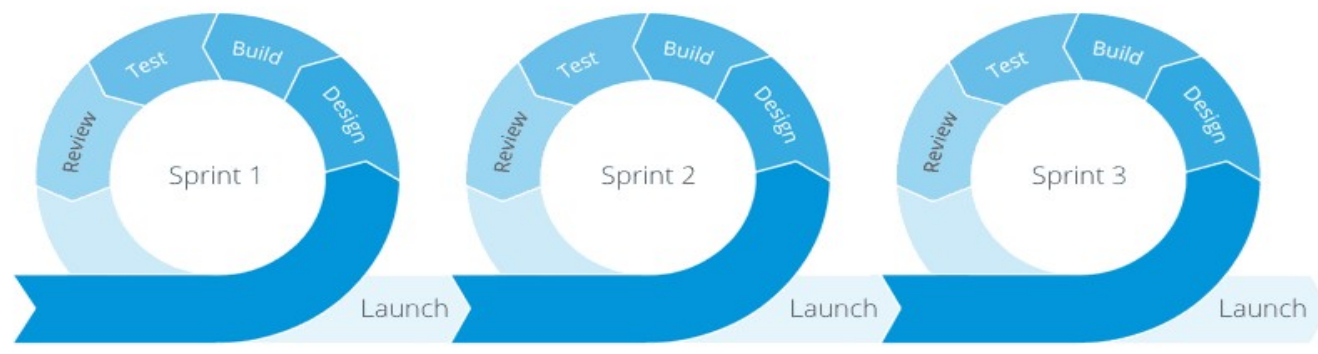

Figure 2. Agile Methodology

\subsubsection{Prototype Methodology}

Prototype methodology is defined as a Software Development model in which a prototype is built, test, and then reworked when needed until an acceptable prototype is achieved. Software prototyping model works best in scenarios where the project's requirement is unknown. It is an iterative, trial, and error method which take place between the developer and the client [14]. 
Prototype methodology knows as known from other fields, such as mechanical engineering or manufacturing. By using this prototype, the client can get an "actual feel" of the system, since the interactions with prototype can enable the client to better understand the requirements of the desired system. Prototyping is an attractive idea for complicated and large systems for which there is no manual process or existing system to help determining the requirements. While, prototype model should be used when the desired system needs to have a lot of interaction with the end users. Prototyping ensures that the end users constantly work with the system and provide a feedback which is incorporated in the prototype to result in a useable system.

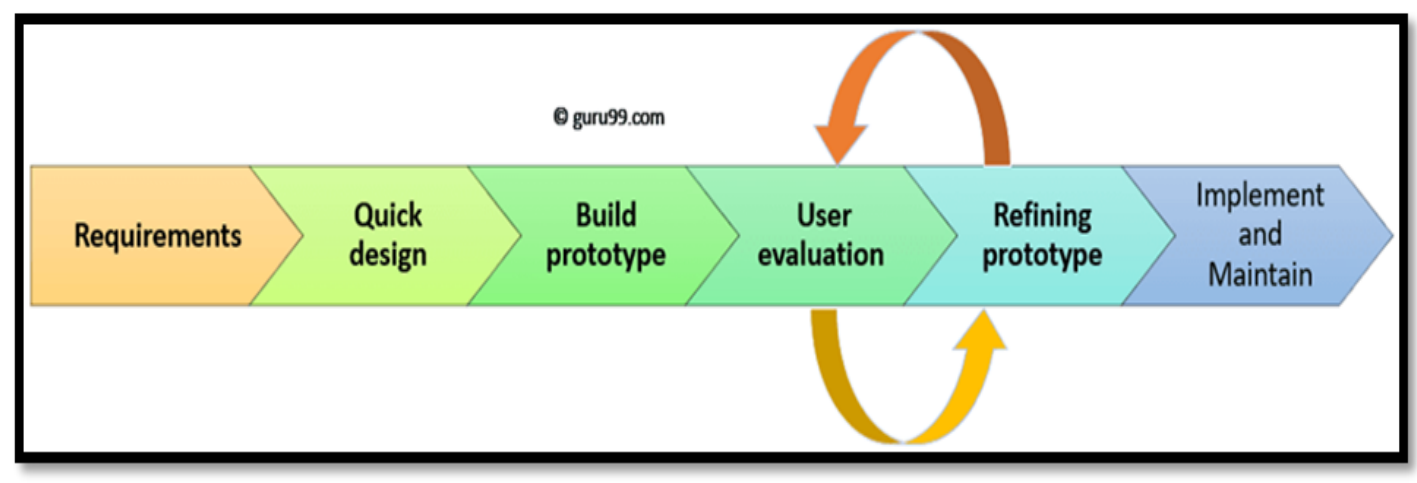

Figure 3. Prototype Methodology

\section{Research Methods}

Methodology used in developing Solar Energy based on IoT is the prototyping methodology. Prototyping methodology is suitable for IoT system development because new system requirements or expectations of the system output are outlined in as much detail as possible [20]. This requires interviewing variety of users, representing all the segments or stakeholders of the prevailing system. Because of that, a preliminary layout specification is formed for the new system. A first output model of the new system is made from the preliminary layouts. This is often a scaled-down system which tentatively gives an approximation of the desired output required. Easy for user check the primary output, noting its strengths and weaknesses, the things which need to be carried ahead in the next steps and the things which need to be discarded. The developer collects and examines the remarks from the all the stakeholders. However, the reasons choosing this methodology for development IoT system because this system more organized, organized and runs smoothly.

\subsection{Requirements Gathering and Analysis}

A prototyping model starts with requirement analysis. In this phase, the requirements of the system are defined in detail. During the process, the users of the system are interviewed to know what their expectation from the system is. For the requirement gathering, they can be divided into several method. Those are document analysis, observation and prototyping. For this research the method that commonly will used is prototyping. Aside from that, a question also has been made for users to answer and found that most respondent think this research will provide more electricity for the home.

\subsection{Quick Design}

The second phase is a preliminary design or a quick design. In this stage, a simple design of the system is created. However, it is not a complete design. The design is drawn in several types diagram which are Use Case Diagram, Activity Diagram and so on. It gives a brief idea of the system to the user. The quick design helps in developing the prototype.

\subsection{Build a Prototype}

For this stage, an actual prototype is designed based on the information gathered from quick design. It is a small working model of the required system. The prototype that will be build must match all the requirement that have already documented earlier to avoid untallied between document and the prototype. 
Table 2. Components Used in Solar Energy

\begin{tabular}{|c|c|c|}
\hline No. & Name & Description \\
\hline 1 & Arduino Uno R3 & $\begin{array}{l}\text { Arduino is and open-source electronic platform based on } \\
\text { easy-to-use hardware and software. }\end{array}$ \\
\hline 2 & Servo Motor & $\begin{array}{l}\text { Servo motor is an electrical device which can push or rotate } \\
\text { an object with great precision. }\end{array}$ \\
\hline 3 & Jumper wire & $\begin{array}{l}\text { Jumper wires are simply wire that have connector pins at } \\
\text { each end, allowing them to be used to connect two points to } \\
\text { each other without soldering. }\end{array}$ \\
\hline 4 & Breadboard & $\begin{array}{l}\text { The breadboard is a platform you can use to build and test } \\
\text { electronic circuits, usually without having to do any } \\
\text { soldering. }\end{array}$ \\
\hline 5 & Resistor & $\begin{array}{l}\text { A resistor is a passive two-terminal electrical component } \\
\text { that implements electrical resistance as a circuit element. }\end{array}$ \\
\hline 6 & $\begin{array}{l}\text { Light Dependent Resistor } \\
\text { (LDR) }\end{array}$ & $\begin{array}{l}\text { It is a one type of resistor whose resistance varies } \\
\text { depending on the amount of light falling on its surface. }\end{array}$ \\
\hline 7 & Current Sensor & $\begin{array}{l}\text { Current sensor is a device that detects electric current in a } \\
\text { wire and generates a signal proportional to that current. }\end{array}$ \\
\hline 8 & Solar Panel & $\begin{array}{l}\text { Solar cell is a device whose electrical characteristics such } \\
\text { as current, voltage and resistance very when exposed to the } \\
\text { sunlight. }\end{array}$ \\
\hline 9 & USB Type-B Cable & $\begin{array}{l}\text { The USB Type B connector (technically known as a } \\
\text { "Standard B" connector) is roughly square in appearance, } \\
\text { with a squarish protrusion on top. }\end{array}$ \\
\hline 10 & Ultrasonic Sensor & $\begin{array}{l}\text { An ultrasonic sensor is an electronic device that measures } \\
\text { the distance of a target object by emitting ultrasonic sound } \\
\text { waves, and converts the reflected sound into an electrical } \\
\text { signal. }\end{array}$ \\
\hline 11 & ESP 8266 & $\begin{array}{l}\text { The ESP8266 WiFi Module is a self-contained SOC with } \\
\text { integrated TCP/IP protocol stack that can give any } \\
\text { microcontroller access to your WiFi network. The ESP } 8266 \\
\text { is capable of either hosting an application or offloading all } \\
\mathrm{Wi-Fi} \text { networking functions from another application } \\
\text { processor. }\end{array}$ \\
\hline
\end{tabular}

\subsection{Initial User Evaluation}

In this stage, the proposed system is presented to the client for an initial evaluation. It helps to find out the strength and weakness of the working model. Comment and suggestion are collected from the customer and provided to the developer.

\subsection{Refining Prototype}

If the user is not happy with the current prototype, you need to refine the prototype according to the user's feedback and suggestions. This phase will not over until all the requirements specified by the user are met. Once the user is satisfied with the developed prototype, a final system is developed based on the approved final prototype.

\subsection{Implement Product and Maintain}

Once the final system is developed based on the final prototype, it is thoroughly tested and deployed to production. The system undergoes routine maintenance for minimizing downtime and prevent large-scale failures. 


\subsection{System Components}

In this section will show how the components of the project been connected and the type of the components that been used to produce this research. Based on Table 2 show that the various types of components used to complete the Solar Energy research.

Based on Figure 4 the main component that seem connected to most of others component is Arduino Uno. The component that connects to Arduino Uno are servo motor, light dependent resistor (LDR) and solar panel.

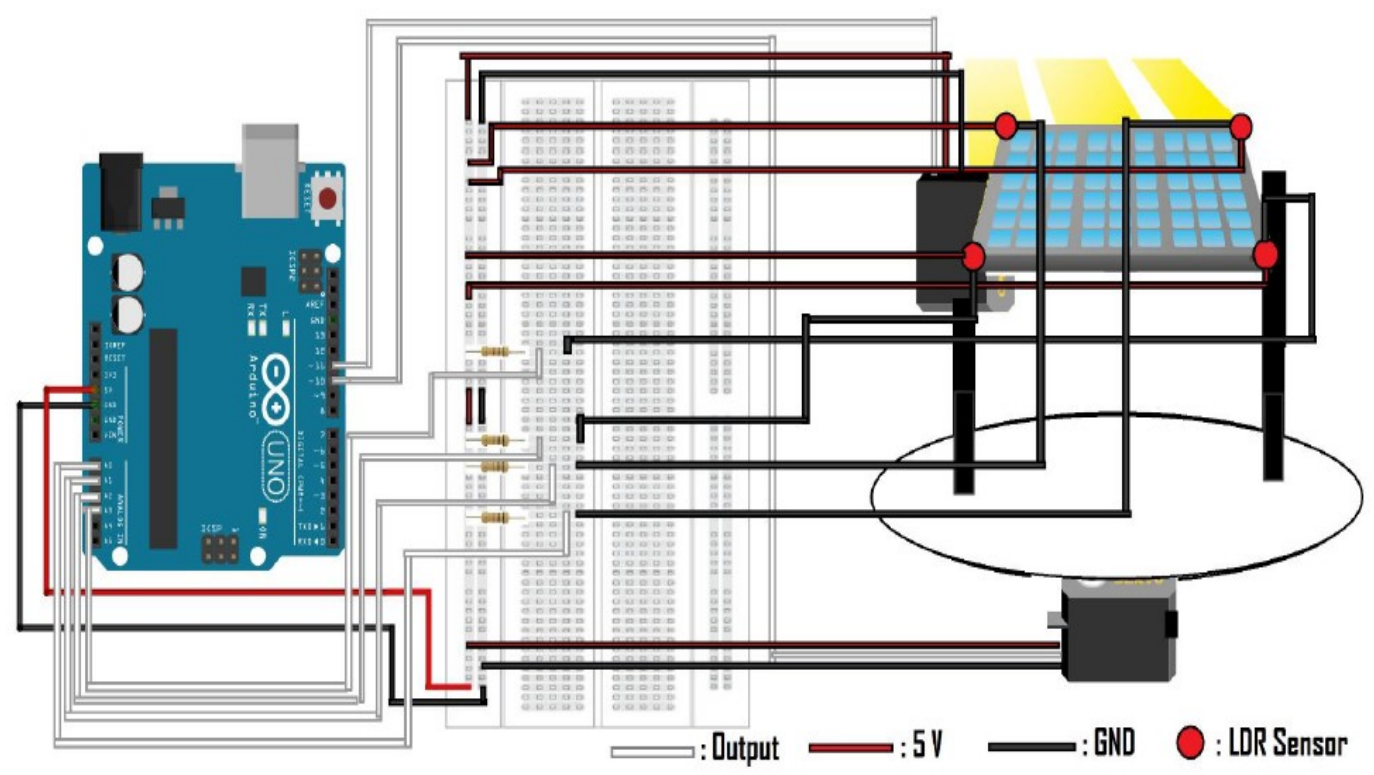

Figure 4. Schematic Diagram of Solar Energy

\section{Results and Discussion}

\subsection{Implementation}

\subsubsection{Arduino Program}

The main function of the Solar Energy is the control function where the user can control the movement of the solar by using smartphone via connection of internet. Based on Figure 5, these are basically how the control movement work. Each movement divided into 3 types; left, right and stop. Each of the movement have their own code to program so that the movement of the solar will follow what the user assigned to go by using smartphone via connection of internet.

Based on Figure 6, these are basically how the automatic movement work. Each movement divided into 3 types; left, right and stop. Each of the movement have their own code to program so that the movement of the solar will follow the direction of the sunlight.

Figure 7 shows that the basically how the voltage from the solar display on the serial monitor. The voltage or energy that absorbs from by the solar from the sunlight will display on the serial monitor.

\subsubsection{Database}

Figure 8 shows that the database of Solar Energy research from the notification. This database makes from the Thinger.io and connect it with the notification.

\subsubsection{User Interface}

User interface is the component where how the user will interact the system. On this research, the main programming language used is $\mathrm{C}$. While using the Blynk application, the user will interact with the system. 
Blynkservo|Arduino 1.8.10

File Edit Sketch Tools Help

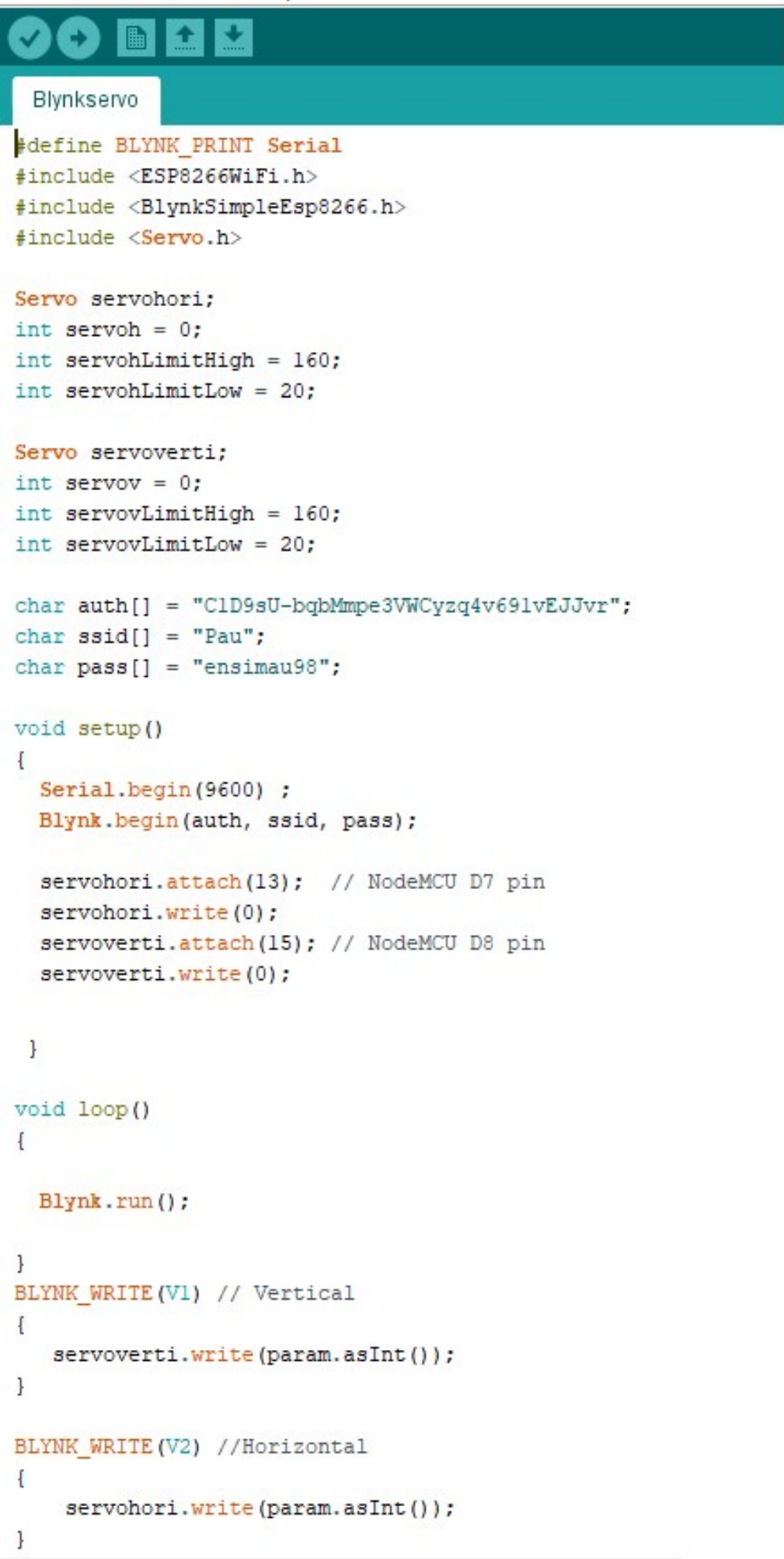

Figure 5. Control Movement Source Code (1) 
servo_motor_Idr|Arduino 1.8.10

File Edit Sketch Tools Help

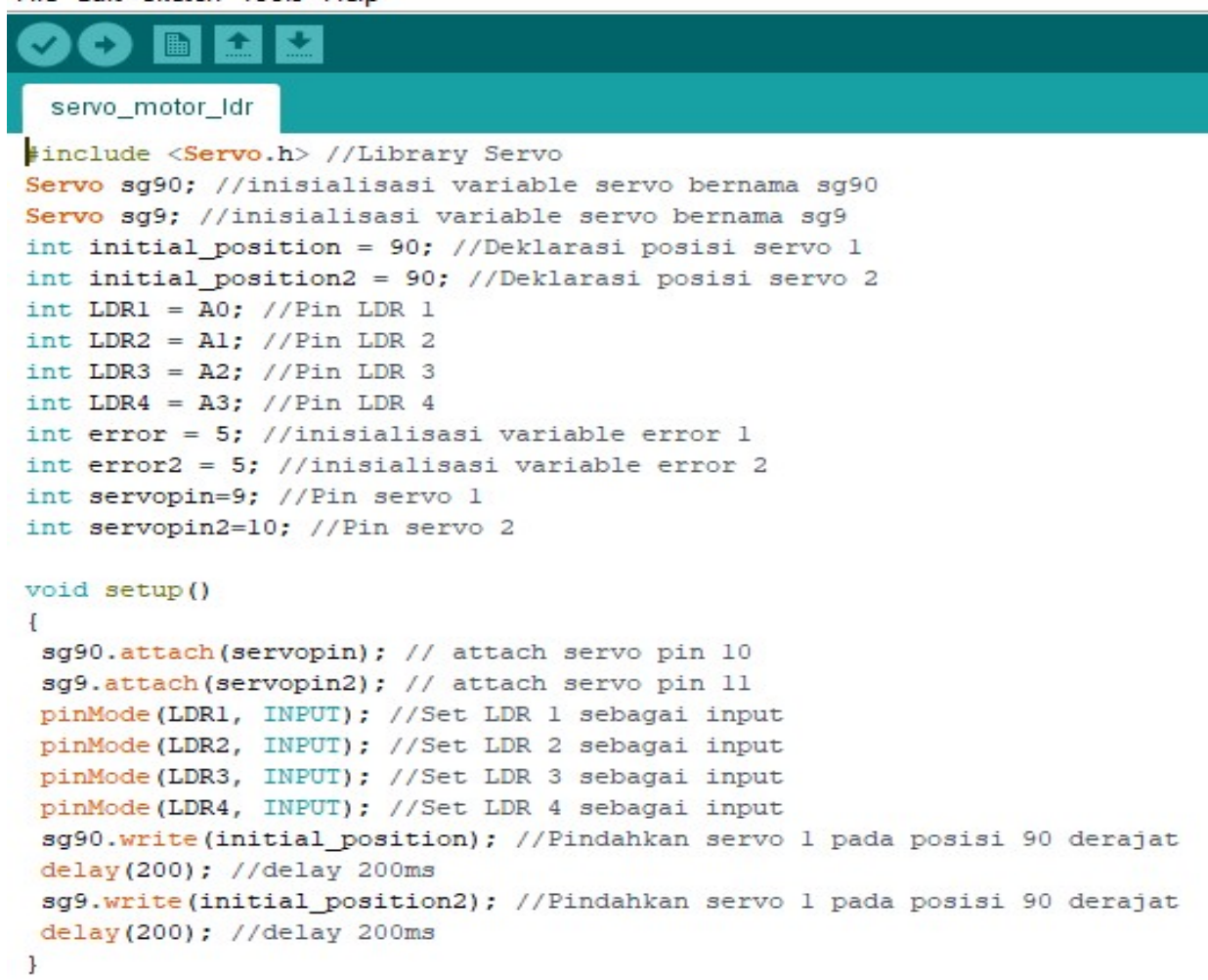

Figure 6. Control Movement Source Code (2)

current_sensor | Arduino 1.8.10

File Edit Sketch Tools Help

\section{$\odot \odot+1 \pm$ Upload}

current_sensor

Measuring Current Using ACS712

*

const int $\operatorname{analogIn}=\mathrm{A} 0$;

int mVperAmp = 185; // use 100 for 20A Module and 66 for 30A Module

int RawValue $=0$;

int ACSoffset $=2500$;

double Voltage $=0$;

double Amps = 0;

void setup ()

Serial begin $(9600)$ :

\}

void loop() f

RawValue $=\operatorname{analogRead}(\operatorname{analog} I n) ;$

Voltage $=($ RawValue $/ 1024.0) * 5000 ; / /$ Gets you mV

Amps $=($ (Voltage - ACSoffset $) /$ mVperAmp $) ;$

Serial.print ("Raw Value $=$ "); // shows pre-scaled value

Serial.print (RawValue)

Serial.print (" $\backslash \mathrm{t} \mathrm{mV}=$ "); // shows the voltage measured

Serial.print(Voltage, 3); // the '3' after voltage allows you to display 3 digits after decimal point Serial.print ("\t Amps = "); // shows the voltage measured

Serial.println(Amps,3); // the ' 3 ' after voltage allows you to display 3 digits after decimal point delay (2500):

Figure 7. Display Voltage Source Code 


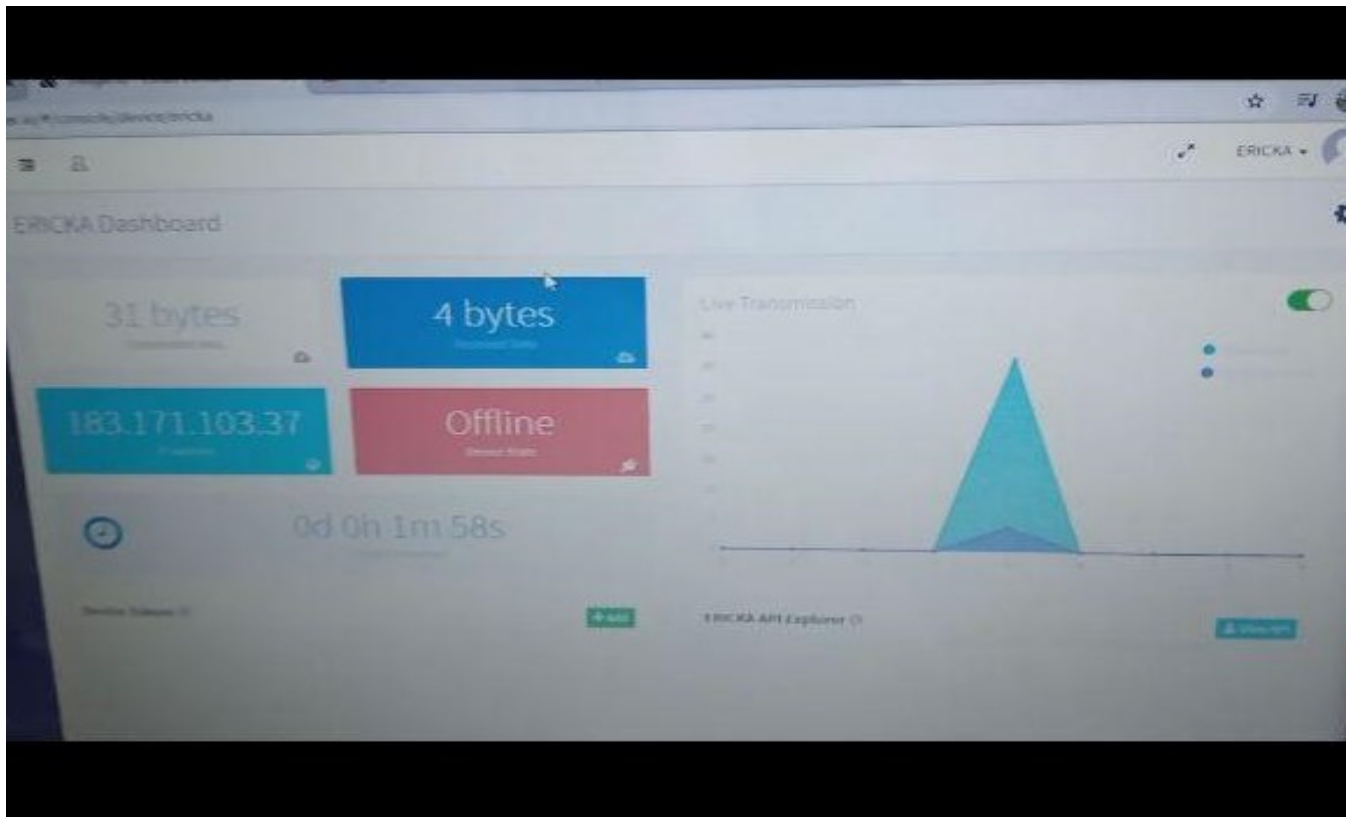

Figure 8. Database

\subsection{Testing}

In this phase, user will test the system in order to know is the requirements have been archived. After the try out, the user will be interviewed and give out the questionnaire to get the feedback from the user after they user Solar Energy.

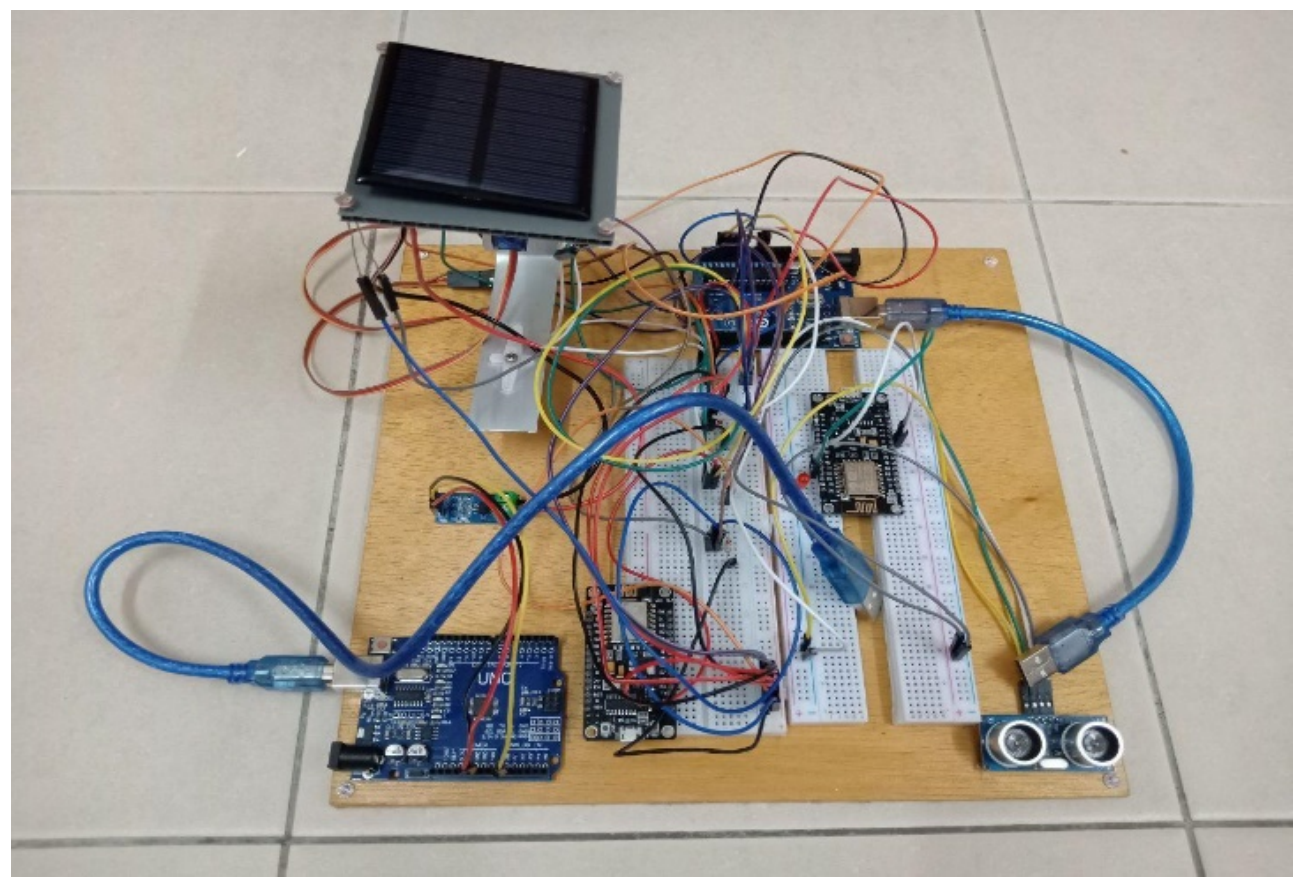

Figure 9. Solar Energy 


\subsection{User Response}

There are several survey responses that users fill for Solar Energy research. This survey shows what user thinks about the Solar Energy research like usability, functionality, performance testing, capability testing and security testing.

\section{Testing for Scenario 1: Usability}

Figure 10 show that about $60 \%$ of respondent from data strongly agree that Solar Energy with IoT notification is useful for current and future generation.

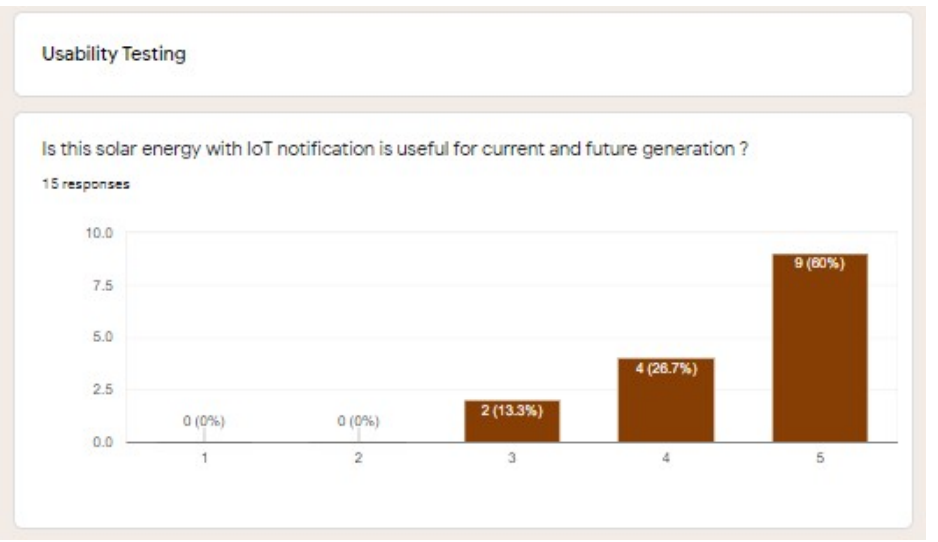

Figure 10. Usability Testing (1)

Figure 11 show that about $60 \%$ of respondent from data strongly agree that Solar Energy it was simple to understand and use the project.

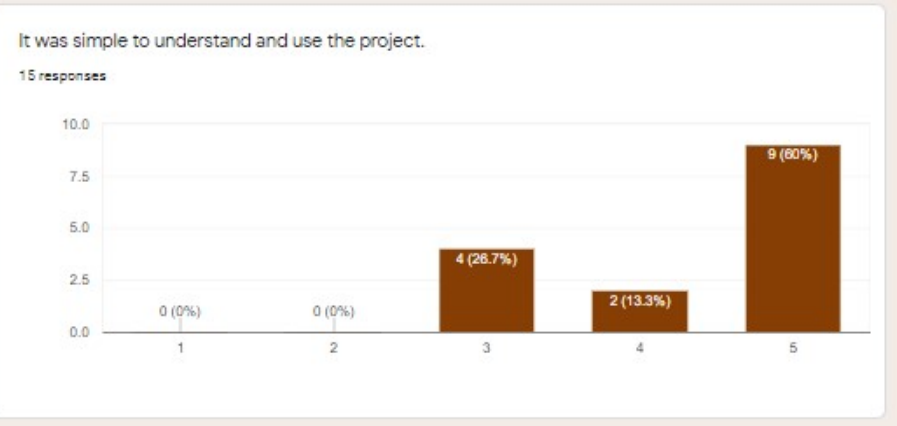

Figure 11. Usability Testing (2)

Figure 12 show that about $46.7 \%$ of respondent from data strongly agree that user was able to monitor the voltage of the Solar Energy. 
I was able to monitor the voltage of the solar energy

15 responses

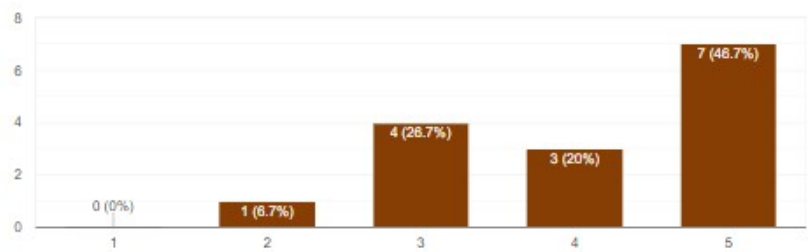

Figure 12. Usability Testing (3)

\section{Testing for Scenario 2: Functionality}

Figure 13 show the functionality testing that about $60 \%$ of respondent from data strongly agree that the movement of solar plate can be controlled using light, which is automatic.

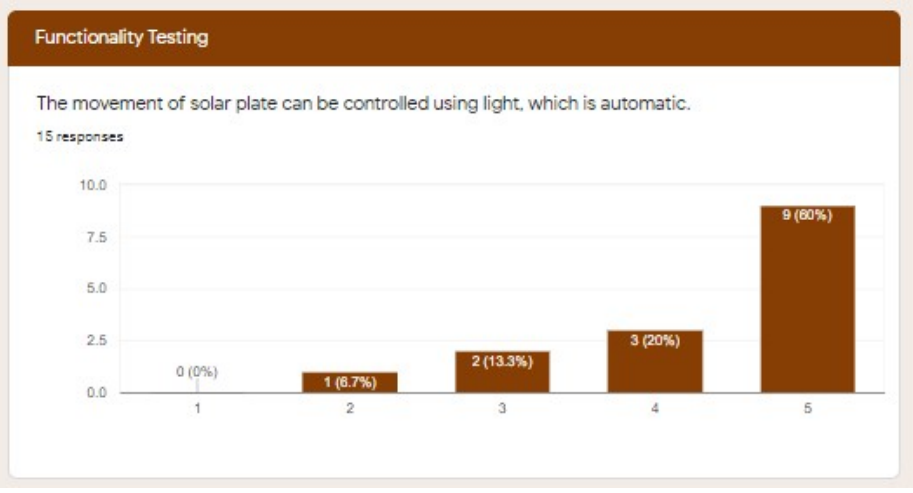

Figure 13. Functionality Testing (1)

Figure 14 show the functionality testing that about $53.3 \%$ of respondent from data strongly agree that the solar movement can also be controlled manually by using mobile phone via connection to internet.

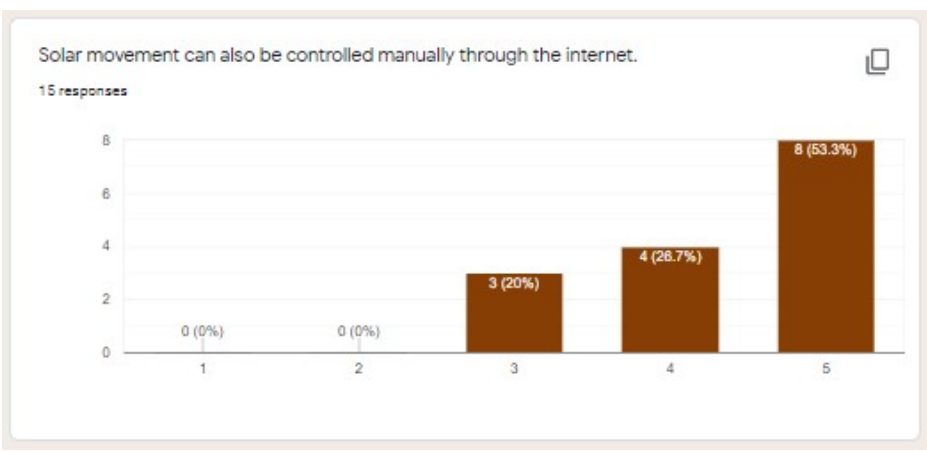

Figure 14. Functionality Testing (2)

Figure 15 show the functionality testing that about $46.7 \%$ of respondent from data strongly agree that the solar can absorb the energy from sun and voltage will display on serial monitor. 


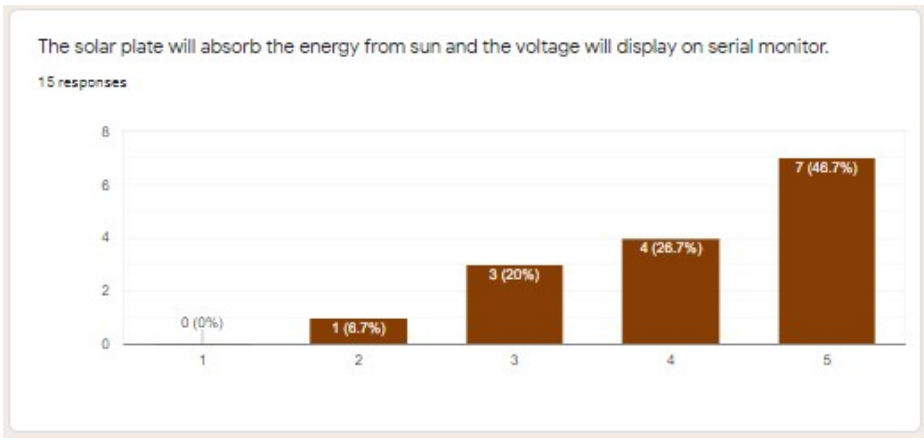

Figure 15. Functionality Testing (3)

Testing for Scenario 3: Performance

Figure 16 show the performance testing that about $66.7 \%$ of respondent from data strongly agree that the functionality of the system in terms of performance.

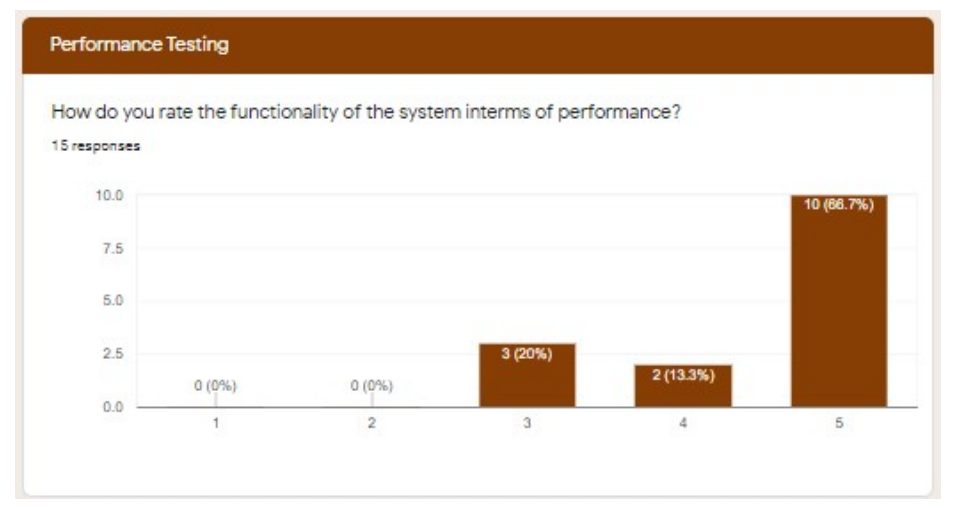

Figure 16. Performance Testing (1)

Figure 17 show the performance testing that about $40 \%$ of respondent from data agree that connection between the blynk application and the Wi-Fi modules is speed.

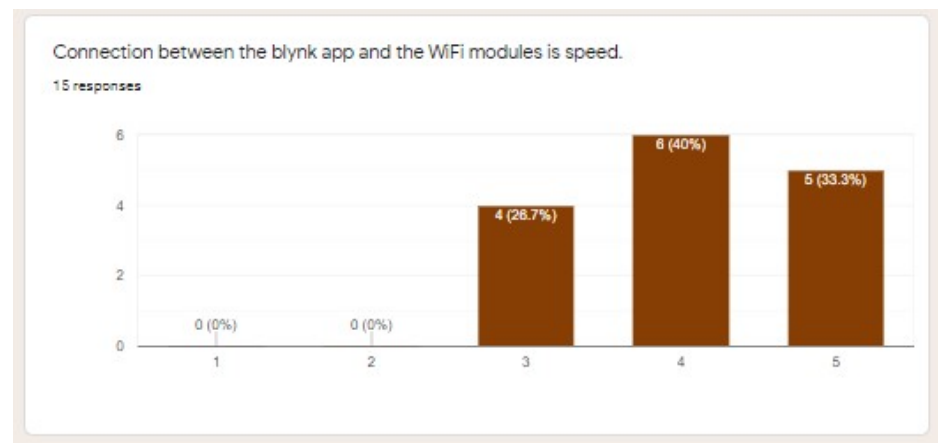

Figure 17. Performance Testing (2)

\section{Testing for Scenario 4: Capability}

Figure 18 show the capability testing that about $66.7 \%$ of respondent from data strongly agree that all the sensor are work together with the components. 


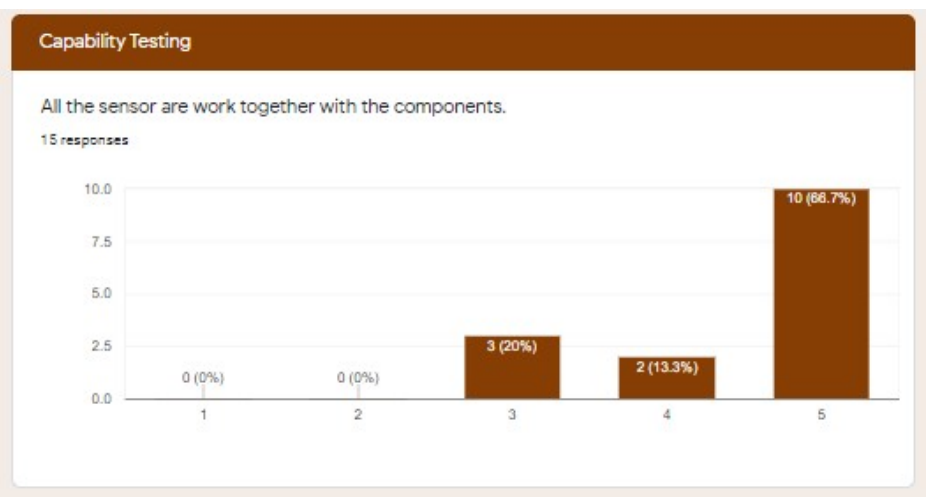

Figure 18. Capability Testing (1)

Figure 19 show the capability testing that about $53.3 \%$ of respondent from data strongly agree that this project connected to internet since it related to Internet of Things.

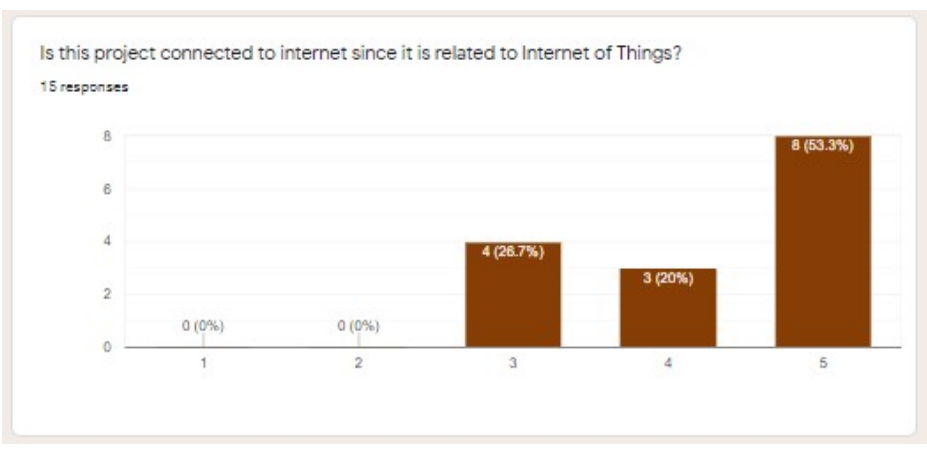

Figure 19. Capability Testing (2)

\section{Testing for Scenario 5: Security}

Figure 20 show the security testing that about $73.3 \%$ of respondent from data strongly agree that this project secure to use by all age people.

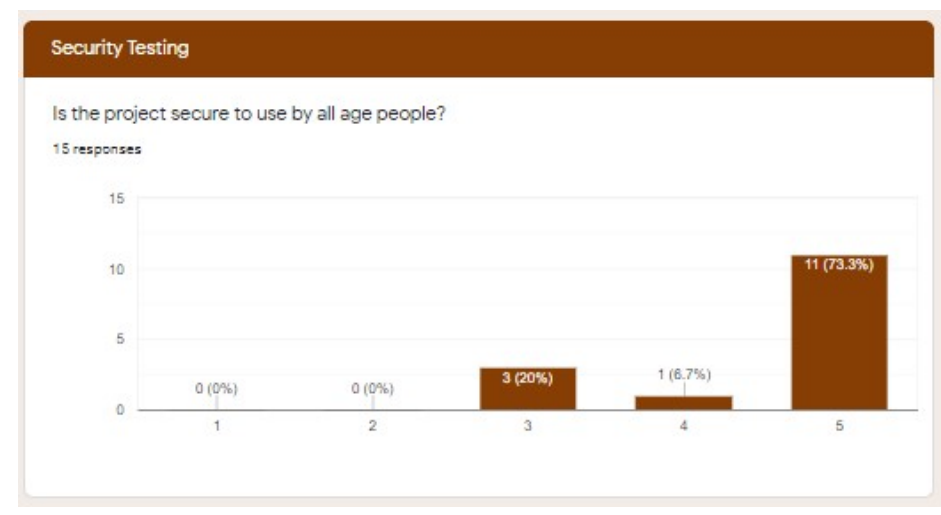

Figure 20. Security Testing (1)

Figure 21 show the security testing that about $60 \%$ of respondent from data strongly agree that this project safe to receiving notification through Blynk application. 


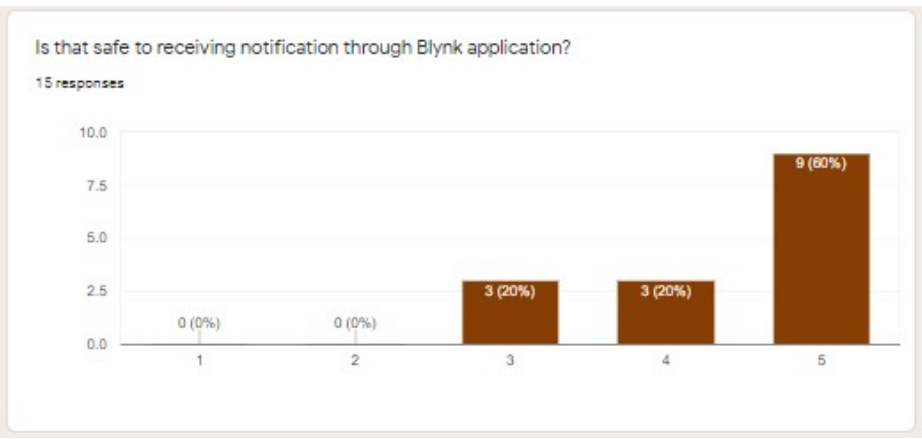

Figure 21. Security Testing (1)

Figure 22 show that about $53.3 \%$ of respondent from data strongly agree that this IoT project have high expectations.

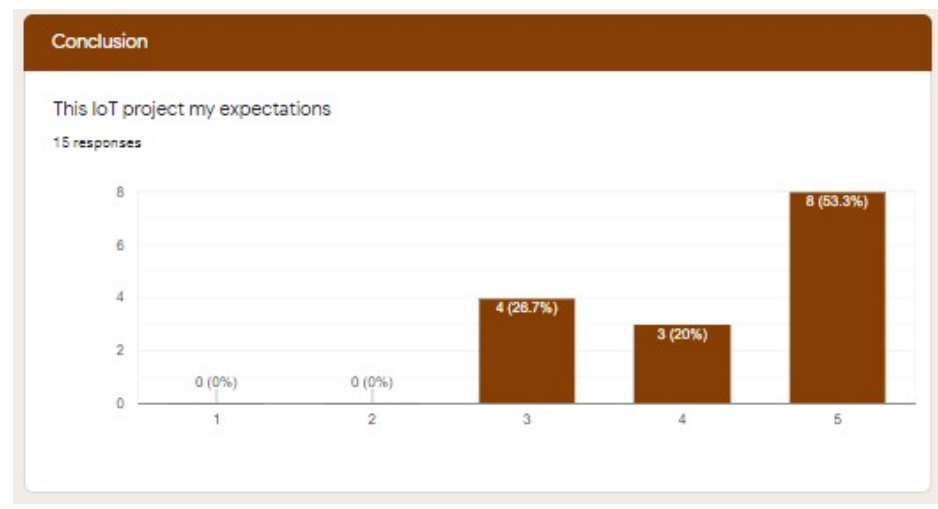

Figure 22. Conclusions (1)

Figure 23 show that about $53.3 \%$ of respondent from data strongly agree that the respondent satisfied with this IoT project.

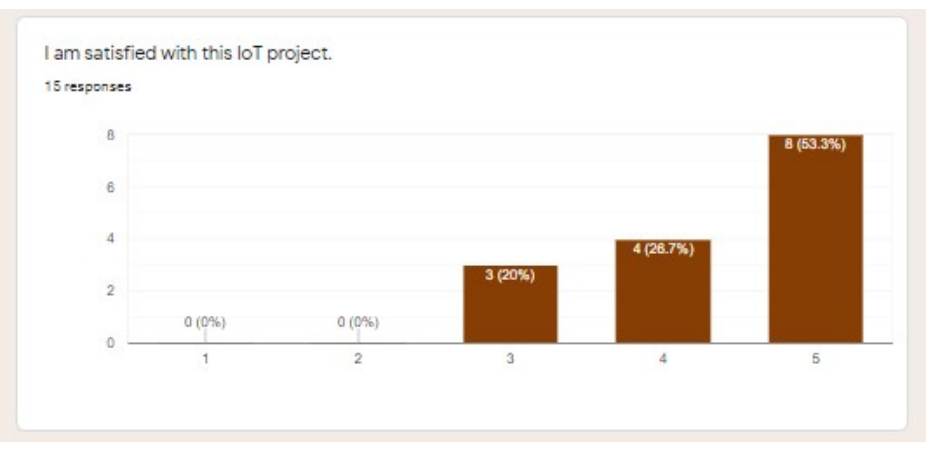

Figure 23. Conclusions (2)

Figure 24 show that about $60 \%$ of respondent from data strongly agree that this project makes the future of IoT is virtually unlimited due to advances in technology. 
This project makes the future of loT is virtually unlimited due to advances in technology.

15 responses

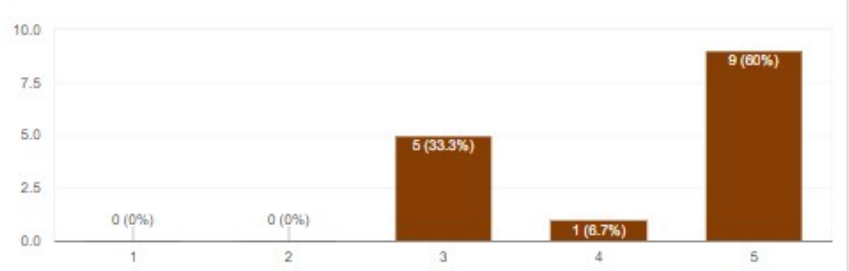

Figure 24. Conclusions (3)

Figure 25 show that about $60 \%$ of respondent from data strongly agree that Wi-Fi has made it possible to connect people and machines on land, in the air and at sea.

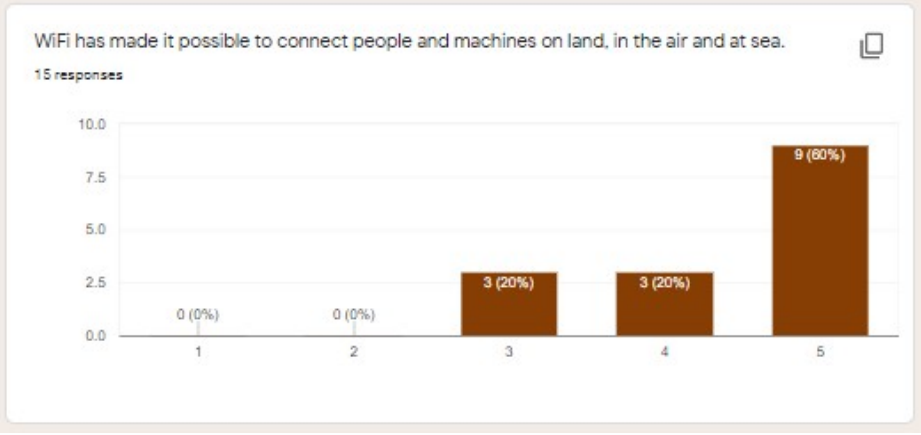

Figure 25. Conclusions (4)

Figure 26 show that about $60 \%$ of respondent from data strongly agree that the possibilities are exciting, productivity will increase and amazing things will come by connecting the world.

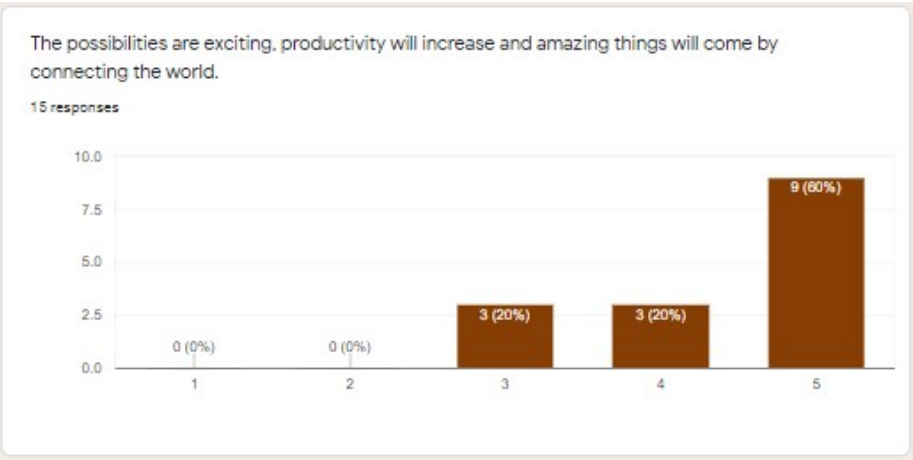

Figure 26. Conclusions (5)

Figure 27 show that about $53.3 \%$ of respondent from data strongly agree that this IoT project will develop the technologies in Malaysia more sophisticated. 


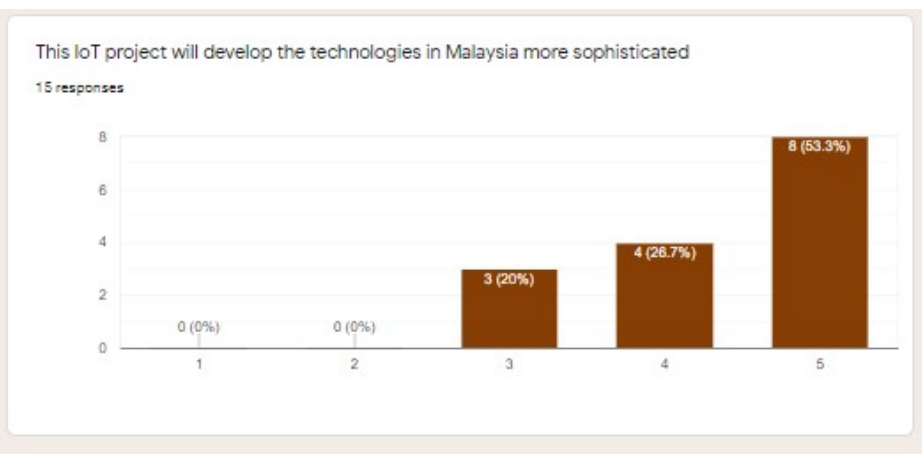

Figure 27. Conclusions (6)

\section{Conclusions}

The research is designed to show the solar movement is controlled over the internet using a mobile phone and sends a message showing how much voltage and energy the solar absorbs to the internet. The purpose of this research is to make it easier for users to control solar and find out how much voltage and energy the solar generates.

There are many problems that occur in the previous type of solar tracking system. The fixed solar panels do not aim directly to the sun due to the constant motion of earth. As the result, the power produced by this Solar Energy is not the maximum of how it should produce. The better solution for this system to get the maximum output power is solar tracking system. This is the main reason the research solar tracker is made. The solar tracker will follow the sunlight to get more output power. Indirectly it will reduce the cost of buying more solar panels. These systems also reduce the time for users to change the position of solar panels to face the sun.

With the objectives have been achieved, the significance of this research can extend in the future. To the researcher who are interested in continuing this system. There are several suggestions for this system that can be done:

1. Integrate with the GPS module in the Solar Energy research.

2. Generate more electricity for home.

3. Controlled the movement of the solar panel through mobile phone via connection internet.

\section{References}

[1] I. Y. Panessai, M. M. Lakulu, S. K. Subramaniam, A. F. Saad, M. I. M. Damanhuri, N. I. Yusuf, "Dual axis sun tracker system based on IoT," Journal of Advanced Research in Dynamical and Control Systems, vol. 10, no. 13, pp. 2379-2394, 2018.

[2] A. Zariman, Muhammad Syazwan bin Abd Latif, and Ammar Asyraf bin Ismail, "Smart Garbage Monitoring", International Journal of Artificial Intelligence, vol. 6, no. 1, pp. 75 - 81, Sep. 2019.

[3] K. B. Azahar, E. E. Sekudan, and A. M. Azhar, "Intelligent Egg Incubator", International Journal of Recent Technology and Applied Science, vol. 2, no. 2, pp. 91-102, Sep. 2020.

[4] N. Saidatin, S. Nurmuslimah, and P. Bagus, "A Design Remote Control System to Feed Birds Using ESP8266", International Journal of Recent Technology and Applied Science, vol. 2, no. 2, pp. 81-90, Sep. 2020.

[5] I. Y. Panessai, M. M. Lakulu, S. K. Subramaniam, A. F. Saad, M. I. M. Damanhuri, N. I. Yusuf, "Developing a Prototype for Sun Tracker System Based on IoT: Controlled by Mobile App and Online Database Monitoring," American Journal of Applied Sciences, vol. 16, no. 1, pp. 11-25, 2019. DOI:10.3844/ajassp.2019.11.25

[6] A. Chandrababu and A. Muddangula, "Adoption of Hybrid methodology in projects," Dissertation, 2020.

[7] S. A. Jumaat, A. A. A. Tan, M. N. Abdullah, N. H. Radzi, R. Hamdan, S. Salimin, and M. N. B. Ismail, "Horizontal Single Axis Solar Tracker Using Arduino Approach," Indonesian Journal of Electrical Engineering and Computer Science, vol. 12, no. 2, pp. 489-496, Nov. 2018. 
[8] Brown Dog Gadgets, "Simple Dual Axis Solar Tracker," Instructables. [15nline]. Available: http://www.instructables.com/id/Simple-Dual-Axis-Solar-Tracker/.

[9] R. L. L. Babu, D. Rambabu, A. R. Naidu, R. D. Prasad, and P. G. Krishna, "IoT Enabled Solar Power Monitoring System," International Journal of Engineering \& Technology, vol. 7, no. 3.12 , pp. 526-530, 2018.

[10] Hermansyah, Kasim, and I. K. Yusri, "Solar Panel Remote Monitoring and Control System on Miniature Weather Stations Based on Web Server and ESP32", International Journal of Recent Technology and Applied Science, vol. 2, no. 1, pp. 1-24, Mar. 2020.

[11] M. A. Azizi and A. Zariman, "Displaying Health Status Based IoT", International Journal of Recent Technology and Applied Science, vol. 2, no. 1, pp. 25-35, Mar. 2020.

[12] F. Abdul Ghani and A. Zariman, "Smart Cane based on IoT", International Journal of Education, Science, Technology, and Engineering, vol. 2, no. 1, pp. 12 - 18, Jun. 2019.

[13] M. H. Hazhari, M. A. Azizi, and A. Zariman, "Smart Delivery Agent", International Journal of Recent Technology and Applied Science, vol. 2, no. 1, pp. 36-47, Mar. 2020.

[14] M. S. Ab Latif, A. A. Ismail, and A. Zariman, "Smart Mirror for Home Automation", International Journal of Recent Technology and Applied Science, vol. 1, no. 1, pp. 1-11, Feb. 2020.

[15] M. H. Husin and I. D. Hisham, "Smart Charger Based on IoT Concept", International Journal of Education, Science, Technology, and Engineering, vol. 2, no. 1, pp. 39 - 44, Jun. 2019.

[16] A. A. Ismail, M. A. Azizi, and A. Zariman, "Smart Water Level Indicator", International Journal of Recent Technology and Applied Science, vol. 2, no. 1, pp. 48-58, Mar. 2020.

[17] M. Verma, "Working, Operation and Types of Arduino Microcontroller," International Journal of Engineering Sciences \& Research Technology, vol. 6, no. 6, pp. 155-158, Jun. 2017.

[18] Y. Bassil, "A Simulation Model for the Waterfall Software Development Life Cycle," International Journal of Engineering \& Technology, vol. 2, no. 5, 2012.

[19] K. Bhavsar, V. Shah, and S. Gopalan, "Scrumban: An Agile Integration of Scrum and Kanban in Software Engineering," International Journal of Innovative Technology and Exploring Engineering, vol. 9, no. 4, pp. 1626-1634, Feb. 2020.

[20] P. Gokhale, O. Bhat, and S. Bhat, "Introduction to IOT," International Advanced Research Journal in Science, Engineering and Technology, vol. 5, no. 1, pp. 41-44, Jan. 2018. 